\title{
Nutritional value of cooked and sous-vide beef: mineral compounds content
}

\author{
$\underline{\text { Monika Modzelewska-Kapituła }}^{1}$, Renata Pietrzak-Fiećko ${ }^{2}$, Katarzyna Tkacz ${ }^{1}$, Adam Więk ${ }^{1}$ and \\ Julia Bogdanowicz ${ }^{1}$ \\ ${ }^{1}$ Department of Meat Technology and Chemistry, Faculty of Food Sciences, University of Warmia and Mazury in \\ Olsztyn, Olsztyn, Poland and \\ ${ }^{2}$ Department of Commodities and Food Analysis, Faculty of Food Sciences, University of Warmia and Mazury in \\ Olsztyn, Olsztyn, Poland
}

\section{Abstract}

Meat, including beef, is a rich source of minerals in the human diet ${ }^{(1,2)}$. However, different thermal treatments might affect minerals concentration in beef and thus its nutritional value. The aim of the study was to determine the degree of coverage of the demand for minerals by consuming $100 \mathrm{~g}$ of steam-cooked and sous-vide beef. Material for the study were semimembranosus muscles $(\mathrm{n}=12)$, cut into $2.5 \mathrm{~cm}$ thick steaks, which were subjected to steam cooking to obtain $75^{\circ} \mathrm{C}$ in geometric centre and sous-vide treatment at $60^{\circ} \mathrm{C}$ for $4 \mathrm{~h}$. The content of minerals was analyzed by flame atomic absorption spectrometry method (flame:acetylene-air). Percentages of the recommended daily allowance (RDA) of $\mathrm{Ca}, \mathrm{Cu}, \mathrm{Fe}, \mathrm{Mg}, \mathrm{Zn}$ and the adequate intake (AI) of $\mathrm{Mn}, \mathrm{K}, \mathrm{Na}$ in $100 \mathrm{~g}$ of thermal processed beef were determined for adults (males and females, aged 19-50 years) and for children (aged 4-8 years) based on the Institute of Medicine, National Academies, recommendations. The concentration of $\mathrm{Ca}, \mathrm{Fe}, \mathrm{Zn}$, and $\mathrm{Cu}$ was higher in steam-cooked beef, whereas $\mathrm{Na}$ and $\mathrm{K}$ in sous-vide beef. Thermal processes beef was very good source of $\mathrm{Zn}$ and Fe; $100 \mathrm{~g}$ of steam-cooked beef satisfied $119 \%$ of Zn RDA for children, $54 \%$ for males and $74 \%$ for females, whereas sous-vide beef $101 \%, 46 \%$ and $63 \%$, respectively. A portion of steam-cooked beef provided $32 \%$ of Fe RDA for children, $40 \%$ for males and $18 \%$ for females, whereas sous-vide beef $21 \%, 26 \%$ and $11 \%$, respectively. The steam-cooked meat was also relatively good source of Cu and provided from $12 \%$ RDA (males and females) to $25 \%$ (children), whereas sous-vide beef from $10 \%$ to $20 \%$, respectively. Thermal processed beef was moderate source for $\mathrm{Mg}$ (from 4 to $13 \%$ of RDA) and $\mathrm{K}$ (from 7 to $9 \%$ of $\mathrm{AI}$ ) and poor source of Ca (up to $0.5 \%$ of RDA), Mn (up to $0.3 \%$ of AI) and $\mathrm{Na}$ (up to $3 \%$ of $\mathrm{AI}$ ). Daily requirements for minerals were satisfied to higher degree by a $100 \mathrm{~g}$ portion of steam-cooked beef, which was caused by lower cooking loss than sous-vide samples.

\section{Acknowledgements}

Project financially supported by Minister of Science and Higher Education in the range of the program entitled "Regional Initiative of Excellence" for the years 2019-2022, Project No. 010/RID/2018/19, amount of funding 12.000.000 PLN.

\section{Conflict of Interest}

There is no conflict of interest

\section{References}

1. Gerber et al. (2009) Meat Science 81, 148-154. doi:10.1016/j.meatsci.2008.07.012

2. Lopes et al. (2015) Meat Science 99, 38-43, doi:10.1016/j.meatsci.2014.08.012 